\title{
Transient inaccuracy in reaching caused by a posterior parietal lobe lesion
}

\author{
JOSÉ M FERRO \\ From the Neurobehavioral Unit, Centro de Estudos Egas Moniz, Department of Neurology, Hospital de Santa \\ Maria, Lisbon, Portugal
}

SUMMARY A transient disturbance of manual reaching in both hemispaces associated with a small contralateral posterior perietal lobe (area 7) lesion is described. This defect was increased when the patient tried to reach without viewing of the affected arm. Inacurate reaching is a distinct syndrome from visuomotor or optic ataxia, and is interpreted as a failure in guiding the arm towards specific sites of the space.

Inaccurate reaching and manual ataxia are consistent findings after posterior parietal lesions in the monkey. ${ }^{1-7}$ This defect is confined to the limbs contralateral to the lesion. In humans unimanual reaching defects affecting both visual fields are very rare and unilateral posterior parietal lesions usually produce visuomotor ataxia of one or both hands in the contralateral half-field. ${ }^{8-11}$ Tzavaras and Masure, ${ }^{12}$ Levine, Kauffman and Mohr, ${ }^{13}$ Perenin et al ${ }^{14}$ described patients who were mostly impaired when they tried to reach with the contralesional arm into both half-fields. Misreaching was interpreted by Levine $e a^{14}$ as due to a loss of posterior parietal neurons subserving a supramodal function of integration of visual and upper extremity sensory and motor information.

We report a patient who had a similar but transient disorder of reaching caused by a small ischaemic left posterior parietal lesion.

\section{Case report}

A 73-year-old right-handed woman came to the emergency room of our hospital complaining of speech disturbance, incoordination of her right hand and of bumping obstacles with her right limbs. These symptoms had suddenly appeared four hours before. Blood pressure was $110-80 \mathrm{mmHg}$ and general physical examination was negative. Neurological examination disclosed fluent speech with abundant circumlocutions and some verbal paraphasias. Understanding of oral commands and naming were

Address for reprint requests: José M. Ferro, M.D., Neurobehavioral Unit, Centro de Estudos Egas Moniz, Hospital de Santa Maria, 1600 Lisboa, Portugal.

Received 25 October 1983, and in revised form 7 March 1984. Accepted 10 March 1984. impaired but repetition was normal. There was a right homonymous hemianopia, flattened right naso-labial fold, an old left peripheral facial palsy and a questionable right extensor plantar response. Limb strength, tonus and deep tendon reflexes were symmetrical. Manual reaching was disturbed with the right hand in both hemispaces and to a minor degree with the left hand in the right hemispace. (We use the term hemispace in the sense defined by Heilman and Valenstein: ${ }^{15}$ the space to one side of the midline of the body).

Routine blood counts and serum chemistry examinations were normal except for an abnormal response on a glucose loading test.

Formal neuropsychological evaluations were carried out on the $3 \mathrm{rd}, 7$ th and 10 th days of illness. On the 3rd day after onset language disturbance assessed with a standardised aphasia battery ${ }^{16}$ was very mild: spontaneous speech was fluent and anomic, confrontation naming was moderately impaired (10 out of 16 objects). Aural comprehension and word and sentence repetition were normal. The patient showed very severe alexia, agraphia and contructional disability: she could neither read or copy (with either hand) letters and her own name, nor copy (with either hand) simple drawings. Her performance on the Benton Fogel Test of three-dimensional constructional praxis was very poor: she scored 4/29 and presented "closing-in" phenomenon. She showed no bucco-facial or limb apraxia, but she was somewhat clumsy when manipulating objects with the right hand. She still presented a right homonymous hemianopia and right threat reflex was absent. Visual fixation, spontaneous conjugate eye movements, slow and saccadic pursuit were normal. Optokinetic nystamus was diminished to the right. Right hand strength and sensation were normal. However, even with free eye and head movements, when she attempted to reach for visual targets, (for example, trying to grasp the examiner's index finger with her index finger and thumb) her right hand performance was impaired in both hemi-spaces, while the left hand performance was accurate. When free eye 
movements were not allowed, by having the patient fixating the examiner's nose while trying to grasp visual targets presented in the left hemi-space (this testing could not be performed in the right hemi-space owing to right hemianopia), the right hand performance deteriorated while the left hand was still accurate. Errors in reaching showed no predominant direction. The right hand stopped some centimeters around the target and then a final corrective movement was made. On other occasions the right hand bumped the examiner's arm and then groped and palpated in order to reach the target. Intention tremor or other involuntary movements were never observed. Pointing to body parts with the right hand was slightly disturbed even with open eyes, but to a less extent than pointing toward extrapersonal targets. Right hand reaching improved after repeated attempts or after the left hand had first grasped the target, and was more accurate when trying to reach a stationary than a moving target.

The patient's condition continued to improve within the next few days. Her speech disturbance had completely cleared by the 7th day of illness. Speech was fluent without anomia or paraphasias. Confrontation naming was normal $(16 / 16)$. Performance on an abbreviated form of the Token test was $100 \%$ correct (22/22). Reading and drawing were unimpaired. When writing she tended to separate letters, by leaving blank spaces between them, a feature that has been described in spatial dysgraphia. ${ }^{18}$ Performance on the Benton-Fogel test was only borderline impaired (22/29). Performance on tests of right-left orientation, digitognosia and gesture recognition were within normal limits. The right visual field defect was restricted to a peripheral crescent. Right hand reaching was also improved. This defect was inconstant, disappearing with practice or if free eye movements were allowed, but was still present in both hemispaces when visual fixation was required. As stated above, the patient's arm and hand movement suffered a final correction when the hand stopped after approaching the target in a wrong direction. This correction was probably dependent on external feedback based on the viewing of the affected limb. To evaluate the role of this feedback the patient was given the following test, adapted from Levine et al: ${ }^{13}$ the projecting limbs were excluded from the patient's view by covering them with a large cardboard with several holes where pinheads were introduced. This cardboard was placed in front of the patient at midthoracic level. The patient was requested to touch, on the undersurface of the board, the lower edge of a pinhead he was seeing on the upper surface of the board. While the left hand (LH) was remarkably accurate, the right hand $(\mathrm{RH})$ inaccurate reaching was strikingly increased, demonstrating the corrective effect of vision upon the movement of the affected limb. We used the Purdue Pegboard and a visuomotor rotor pursuit test (Pursuit Rotor MK4, Forth Instruments Ltd) in order to quantify the right hand defect. Although hand grip (measured with a dynamometer) and a tapping test gave comparable results for both hands, the performance of the RH was inferior to that of the LH on the Purdue Pegboard (time to range a row of pegs: $\mathrm{RH}=$ $164^{\prime \prime}, \mathrm{LH}=120^{\prime \prime}$ ) and on the visuo-motor pursuit task (mean total time on target on five trials of $20^{\prime \prime}$ each: $\mathrm{RH}=$ $7.39 \pm 4.13 \mathrm{sec}, \mathrm{LH}=3.99 \pm 2 \cdot 40, \mathrm{t}=1.59, \mathrm{p}<0.05)$.

By the 10th day the right-hand reaching disorder was no longer present, except for some hesitancy when pointing to rapidly moving targets. The $\mathrm{RH}$ had regained its usual superiority on the Purdoe Pegboard (RH $=67^{\prime \prime}, \mathrm{LH}=$ $\left.79^{\prime \prime}\right)$ but was still slightly slower on the visuomotor pursuit task $(\mathrm{RH}=2.95 \pm 1.20 ; \mathrm{LH}=2.66 \pm 1.07 ; \mathrm{NS})$. The CT-scan disclosed a discrete ischaemic lesion involving a small area of the left posterior parietal cortex (Brodman's area 7) and subjacent white matter, (fig). The lesion could be traced in three consecutive cuts, each being $1 \mathrm{~cm}$ thick.

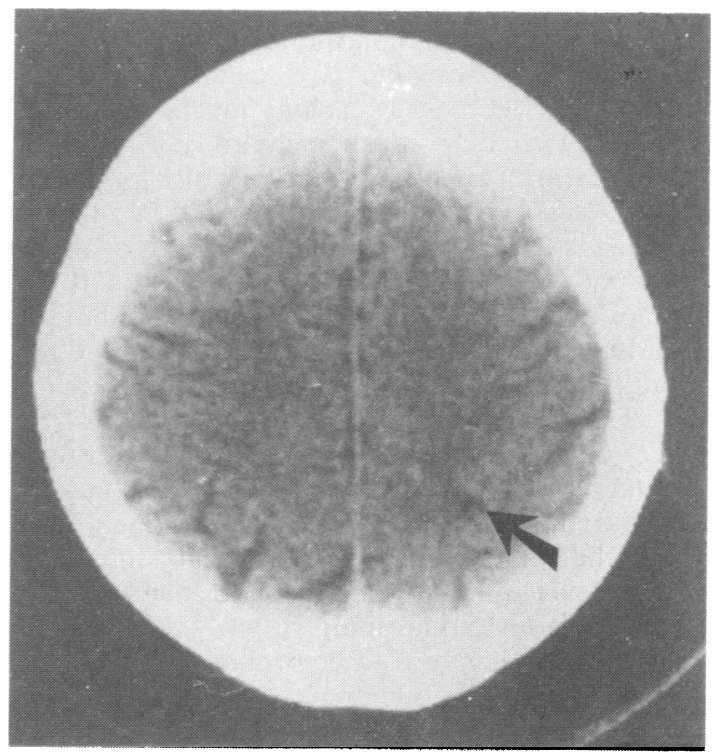

Fig CT scan demonstrating a small infarct (arrow) involving the left superior parietal lobe.

\section{Discussion}

This woman presented a transient disturbance of reaching with the right hand associated with a small contralateral superior parietal lobe lesion. During the first few days of disease signs of involvement of surrounding areas were also present: alexia and agraphia, severe constructional disability and fluent (transcortical sensory) aphasia.

In humans, posterior parietal lobe lesions can cause visuo-motor ataxia of one or both hands in the contralateral hemifield.$^{8-11}$ Following a posterior parietal lobe lesion, monkeys became impaired when trying to reach with the contralateral arm in both half-fields of extrapersonal space. ${ }^{1-7}$ Tzavaras and Masure ${ }^{12}$ (case 1), Levine et al $^{13}$ and Perenin et $\mathrm{al}^{14}$ (case 2) recently described a corresponding human syndrome. As in our case, Levine's and Perenin's patients also had posterior parietal lesions. The disturbance of manual reaching displayed by our patient can be interpreted either as a visuomotor 
disconnection or as a failure in guiding the arm toward specific sites of the space. Although a right hemianopsia was present during the first days of disease, it cannot be considered the cause of this defect, as reaching was incorrect in both hemispaces, and in the right one even with free eye movements. Moreover the patient's reaching behaviour suggested that vision could improve her performance. In fact, after an initial incorrect movement toward the target, vision-guided terminal correction was made to grasp it. The importance of this visual correction and of viewing the moving limb was demonstrated by the increased reaching innaccuracy when the patient tried to reach without viewing of the affected arm. This effect, that was also present in Levine's case, is in agreement with the fact that, in monkeys, the reaching disturbance is aggravated in the dark. ${ }^{36}$ It also stresses that this patient's trouble was not due to a visuomotor disconnection but to a disturbance in commanding operations with the contralateral limb towards specific points of the space. This is in accordance with electrophysiological evidence. Several researchers found, in the posterior parietal lobe of the behaving monkey, cells that had no apparent sensory input but were extremely active when the animal reached into the immediate extrapersonal space to obtain or to manipulate an object of motivational interest. ${ }^{19}{ }^{20}$ About $20 \%$ of these cells are active with contralateral movements towards either half of the space. ${ }^{19}$ Loss of these cells, caused by a posterior parietal lobe lesion, can explain the patient's inacurate reaching.

In visuomotor ataxia and in the patient described by Tzavaras and Masure, ${ }^{12}$ both the initial arm projection and the terminal visually guided movement to the target were affected. In Levine' $\mathrm{s}^{13}$ and our case, if vision of the moving arm was allowed, the final adjustment to the target was correct. This adjustment needs intact striate visual cortex ${ }^{21}$ while arm projection seems to depend more on parietal cortex (area 7), that receives visual information indirectly from the peristriate area, the pulvinar and the superior colliculus. ${ }^{22}$ The visually guided terminal adjustment may depend on direct intact occipito-frontal connexions, ${ }^{21}$ or visual indirect input to non-damaged portion of the posterior parietal lobe. Indeed, by means of a parietal leucotomy severing occipito-frontal connexions, Haaxma and Kuypers ${ }^{23}$ produced a disturbance of visual guidance of hand and arm movements but leaving the arm projection unaffected.

Tzavaras and Masure ${ }^{12}$ and Perenin et al ${ }^{14}$ suggested that defects of visuo-motor coordination may present different aspects accordingly to the hemispheric side of lesion. Right hemispheric lesions would produce "field-effect", that is, direct and crossed optic ataxia in the contralateral hemifield, while left-sided lesions would cause "hand-effect", that is, a disturbance of reaching with the contralateral hand in both hemifields. Unilateral reaching defects affecting both fields were caused by left vascular lesions in Tzavaras and Masure, ${ }^{12}$ Perenin et $a l^{14}$ and in the present case, and by a right hemispheric tumour in Levine's report. ${ }^{13}$ However, left hemispheric lesions can also produce a hemifield effect. ${ }^{8}$ Reports of unilateral reaching defects are, at the present time, too few to enable a confirmation of the suggestions of Tzavaras and Masure ${ }^{12}$ and Perenin et al. ${ }^{14}$

This case also illustrates the compensatory mechanisms that help manual reaching: (a) viewing of the moving arm enables a final corrective movement and is probably dependent on occipito-frontal connexions; (b) allowance of free eye movements, either because central vision increases the visual input to the parietal cortex or because gaze movements provide extraretinal spatial information, via mesencephalon, superior colliculus and pulvinar; (c) grasping the target with the opposite hand, gives an external clue (view of the moving arm) and proprioceptive feedback that helps in visuo-spatial localisation; (d) practice; (e) a stationary target.

While in Levine's patient the lesion was a large parietal tumour, in our patient the ischaemic area was quite small. This may account for the rapid recovery that was probably dependent on the remaining spared area of left posterior parietal lobe. In monkeys the effect of removal of the posterior parietal lobe is also transient, lasting about 15 days, but the extent of the lesions did not appear to be the only factor in this rapid recovery, that could be accelerated by practice. ${ }^{24}$

We thank Dr Medina for performing the CT scan, Dra Angela Gonçalves for assistance in testing and M Fátima Pereira for typing. This work was supported in part by a grant from the Gulbenkian Foundation.

\section{References}

' Ettlinger G, Kalsbeck JE. Changes in tactile discrimination and in visual reaching after successive and simultaneous bilateral posterior parietal ablations in the monkey. J Neurol Neurosurg Psychiatry 1962;25: 256-68.

${ }^{2}$ Ratcliff G, Ridley RM, Ettlinger G. Spatial disorientation in the monkey. Cortex 1977;13:62-5.

${ }^{3}$ Hartje W, Ettlinger G. Reaching in light and dark after unilateral posterior parietal ablations in the monkey. Cortex 1973;9:346-54.

${ }^{4}$ Denny Brown D, Yanagisawa N, Kirk EJ. The localization of hemispheric mechanisms of visually directed 
reaching and grasping. In: Zulch $\mathrm{KJ}$, Creutzfeldt $\mathrm{O}$, Galbraith GC eds. Cerebral Localization Berlin: Springer-Verlag, 1975;62-75.

${ }^{5}$ Devel R. Loss of motor habits after cortical lesions. Neuropsychologia 1977;15:205-15.

- La Motte RH, Acuna C. Defects in accuracy of reaching after removal of the posterior parietal association cortex in monkeys. Brain Res 1978;139:309-26.

${ }^{7}$ Stein JF. The effect of cooling parietal areas and 7 upon voluntary movement in awake rhesus monkey. $J$ Physiol (Lond) 1976;258:62-3.

${ }^{8}$ Riddoch G. Visual disorientation in homonymous halffields. Brain 1935;58:376-82.

9 Castaigne P, Pertuiset B, Rondot P, De Recondo J. Ataxie optique dans les deux hémichamps visuels homonymes gauches aprés exérèse chirurgicale d'un anéurysme arteriel de la paroi du ventricle latéral. Rév Neurol (Paris) 1971;124:261-8.

${ }^{10}$ Castaigne P, Rondot P, Dumas JLR, Tempier P. Ataxie optique localisée au coté gauche dans les deux hemichamps visuels homonymes gauches. Rév Neurol (Paris) 1975;131:23-8.

" Rondot P, De Recondo J, Dumas JLR. Visuomotor ataxia. Brain 1977; 100:355-76.

12 Tzavaras A, Masure MC. Aspects différents de l'ataxie optique selon la latéralisation hémisphérique de la lesion. Lyon Méd 1976;236:673-83.

${ }^{13}$ Levine DN, Kevin JK, Mohr JP. Inaccurate reaching associated with a superior parietal lobe tumor. Neurology (Minneap) 1978;28:556-61.

${ }^{14}$ Perenin MT, Vighetto A, Mauguiere F, Fischer C. L'ataxie optique et son interêt dans l'étude de la coordination oeil-main. Lyon Méd 1979;142:166-70.
${ }^{15}$ Heilman KM, Valenstein E. Mechanisms underlying hemispatial neglect. Ann Neurol 1979;5:166-70.

${ }^{16}$ Ferro JM, Santos ME, Castro Caldas A, Mariano MG. Gesture recognition in aphasia. J Clin Neuropsychol 1980;2:277-92.

17 Benton AL, Fogel ML. Three-dimensional constructional praxis: a clinical test. Arch Neurol 1962;7:347-54.

${ }^{18}$ Marcie P, Hécaen H. The Agraphias. In: Heilman KM, Valenstein E, eds. Clinical Neuropsychology. New York: Oxford University Press, 1979;92-127.

${ }^{19}$ Hyvären J, Poranen A. Function of the parietal associative area 7 as revealed from cellular discharges in alert monkeys. Brain 1974;97:673-92.

${ }^{20}$ Mountcastle VB, Lynch JC, Georgopoulos A, Sakata H, Acuna C. Posterior parietal association cortex of the monkey: command functions for operations within extrapersonal space. J Neurophysiol 1975;38:871908.

${ }^{21}$ Paillard J, Beaubation D. De la coordination visuomotrice a l'organization de la saisie manuelle. In: Hécaen H, Jeannerod M, eds. Du Contrôle Moteur à l'Organization du Geste. Paris: Masson, 1978;225-60.

${ }^{22}$ Yin TCT, Mountcastle VB. Visual input to the visuomotor mechanisms of the monkey's parietal lobe. Science 1977;197:1381-3.

${ }^{23}$ Haaxma R, Kuypers HGJM. Intrahemispheric cortical connexions and visual guidance of hand and finger movements in the rhesus monkey. Brain 1975;98: 239-60.

${ }^{24}$ Faugier-Grimaud S, Frenois C, Stein DG. Effects of posterior parietal lesions on visually guided behavior in monkeys. Neuropsychologia 1978;16:151-68. 